\title{
TOWARD A PHYLOGENY OF MAXILLARIINAE ORCHIDS: MULTIDISCIPLINARY STUDIES WITH EMPHASIS ON BRAZILIAN SPECIES
}

\author{
Rodrigo B. Singer \& Samantha Koehler \\ Departamento de Botânica, I.B., Universidade Estadual de Campinas \\ Campinas, SP, Brazil, 13083-970. rbsinger1@yahoo.com
}

It has been demonstrated that the neotropical subtribe Maxillariinae comprises a well-supported monophyletic orchid group, according to cladistic analyses of nuclear and chloroplast DNA regions (Whitten et al. 2000). The results presented by Whitten et al. (2000) brought to light significant changes concerning the delimitation of the subtribe Maxillariinae. First, in order to avoid the description of an additional subtribe within the Maxillarieae to place the genus Xylobium Lindl., orchids formerly assigned to the subtribes Lycastinae and Bifrenariinae (Dressler 1993), including Xylobium, were merged into a broader Maxillariinae. This taxonomic decision is also supported by floral and vegetative characters. Second, it has been demonstrated that Maxillaria Ruiz \& Pav., by far the largest genus in the subtribe, is polyphyletic, since species of Cryptocentrum Benth., Chrysocycnis Linden \& Rchb.f., Mormolyca Fenzl and Trigonidium Lindl. appeared nested within Maxillaria (M. Whitten and N. Williams, pers. comm.). Once again, this seems to be a very reasonable finding, since Maxillaria as currently accepted comprises plants with extremely dissimilar vegetative architectures.

In order to contribute with the reevaluation of the generic boundaries within the subtribe Maxillariinae (sensu Whitten), a team of Brazilian researchers, including molecular and field biologists as well as chemists has been brought together in a multidisciplinary project. Our goals are (1) to conduct morphological studies of vegetative and flower features of representative species; (2) to determine the chemical structure of flower rewards and fragrances of representative species; (3) to perform pollination and breeding system studies with representative species and; (4) to perform sequencing of multiple DNA regions (nrITS,
trnL-F, matK, atpb) of Brazilian Maxillariinae species with emphasis on Brazilian endemic groups, in collaboration with W.M. Whitten and N.H. Williams (Florida Museum of Natural History, University of Florida, U.S.A.). Here we present a brief account of the results of morphological studies, with emphasis on variability of flower features, especially pollinarium morphology, among different alliances of Brazilian Maxillariinae species. Infrageneric classification into alliances follows Pabst \& Dungs (1977).

Acquisition of specimens. The existence of two large living orchid collections in the state of São Paulo, located at the "Instituto de Botânica de São Paulo" and at the "Escola Superior de Agronomia Luiz de Queiroz" has allowed the collection of samples for DNA studies as well as of fresh flowers for morphological studies. The cultivation of plants also makes possible the observation and comparison of the vegetative architecture of different species. Another advantage of such complete living collections is the possibility to conduct breeding system studies as well as to observe eventual pollinators, as many bee species occur in the area of the collections. Voucher materials of the individuals sampled are being deposited at the SP and UEC herbaria.

Morphological features. Vegetative features are known to present large variation within the Maxillariinae. Plants may or may not bear pseudobulbs and the rhizome, when present, may be long and apparent or extremely short. The number of leaves may vary from one to three in Brazilian species. Flower features are quite conservative. The lip is articulated (rarely fused) to the base of the column. The anther is incumbent and holds a pollinarium with four pollinia. The pollinarium always bears a well- 

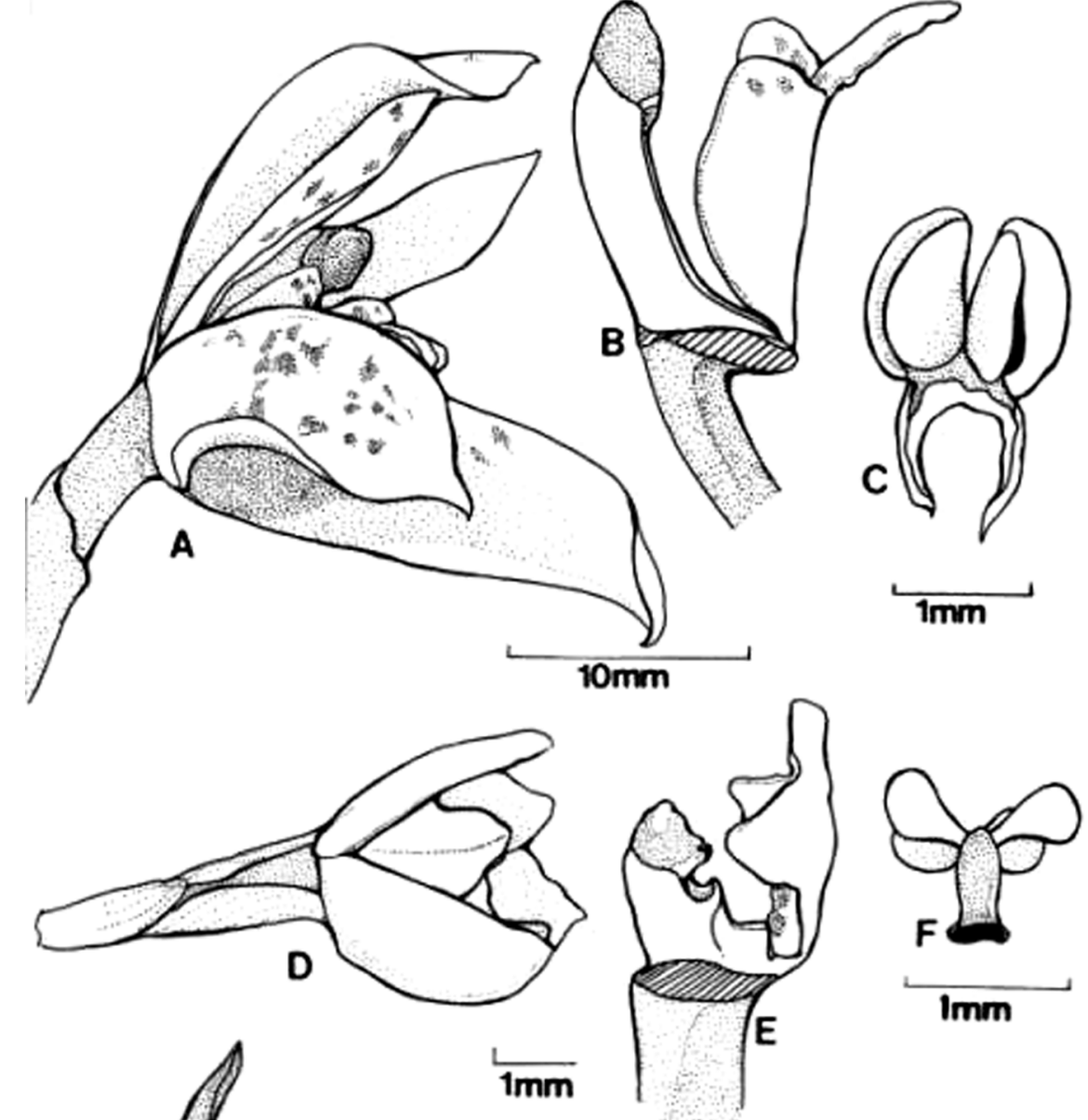

$1 \mathrm{~mm}$
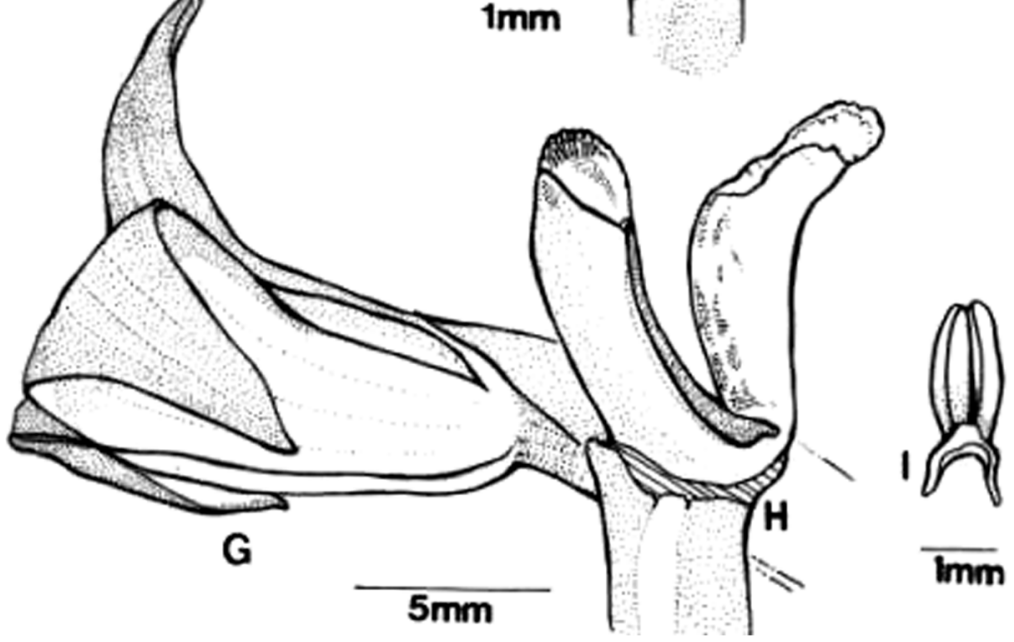

$\overline{\mathrm{mm}}$

Figure 1. Examples of studied taxa of Maxillariinae. A-C. Maxillaria picta Hook. A. Flower in lateral view. B. Column, with lip hinged at its base. C. Pollinarium. D-F. Maxillaria parviflora (Poepp. \& Endl.) Garay. D. Flower in lateral view. E. Lip and column in lateral view. F. Pollinarium. G-I. Trigonidium obtusum Lindl. G. Flower in lateral view. H. Column with lip hinged at its base. I. Pollinarium. 
developed viscidium. Pollinium stalks (namely, tegular stipes) may or not be present.

Some vegetative and flower features appeared to be highly conservative within the Maxillaria alliances studied. Interestingly, these morphological conservative alliances appeared as monophyletic groups according to preliminary molecular data (M. Whitten, pers. comm.). The 'Maxillaria picta' alliance comprises species whose pseudobulbs are always bifoliate. Besides, flowers of this orchid assemblage are generally rewardless and present pollinaria devoid of stipes. The 'Maxillaria madida' alliance possesses a different and remarkable situation. Whereas vegetative features, such as the number and width of the leaves and length of the rhizome, are quite variable, the flowers present an extremely similar morphology. Up to this moment, species from this alliance have shown to be rewardless, the flowers being yellowish, brownish or vinaceous and displaying a shining, smooth labellum. Pollinarium structure is also very conservative within this alliance, with most species bearing a semilunar, often thickened viscidium, attached to large tegular stipes.

Moreover, both the 'Maxillaria discolor' and the 'Maxillaria valenzuelana' alliances present rewarding flowers (with trichomes, wax-like or resin-like compounds) and very similar pollinarium structure, since most species show a semilunar viscidium and large tegular stipes. Preliminary molecular data suggest these alliances are close related (M. Whitten, pers. comm.). They include species either with unifoliate pseudobulbs or without pseudobulbs, as Maxillaria valenzuelana (A. Rich.) Nash and M. equitans (Schltr.) Garay, respectively. Similar vegetative shifts (unifoliate pseudobulbs to pseudobulbless plants) have already been verified in well-supported monophyletic groups of Oncidiinae, namely the NotyliaMacroclinium and Erycina-Psygmorchis complexes (Williams et al. 2001). The loss of the pseudobulb in Maxillariinae may represent a heterochronic shift with retention of seedling morphological features (neoteny), as already suggested for Oncidiinae (Chase 1986).

Reproductive biology. Field observations by R.B. Singer indicate that Hymenoptera, especially Meliponinae bees, are the main pollinators of
Brazilian Maxillariinae. Flower, and particularly, the pollinarium structure are well suited for this kind of pollinators. The well-developed semilunar viscidium embraces the scutellum of the Hymenopteran pollinator when the insect retreats the flower. Such pollinarium deposition is ecologically significant, since the scutellum is a difficult place for the insects to clean. Noteworthy, Maxillaria species that present round, pad-like viscidia, such as Maxillaria parviflora (Poepp. \& Endl.) Garay, have pollinaria deposition on the face of their pollinators. To date, we have recorded bumble-bee and Euglossine pollination in Bifrenaria harrisoniae (Hook.) Rchb.f., ant and bee (Meliponini) pollination in M. parviflora, and Meliponinae and wasp pollination in several species of the 'Maxillaria picta' alliance. Pollination through pseudocopulation mediated by Plebeia (Meliponinae) drones was recently confirmed in Trigonidium obtusum Lindl. (Singer 2002). We also have found nectar in M. rigida Barb. Rodr. and M. parviflora.

In the past, flower features have been widely used in orchid taxonomy. However, it seems that vegetative features are less subject to homoplasy in the subtribe Maxillariinae and we should pay more attention to these characters in phylogenetic studies. A good example of this is the old concept of Oncidium Sw. Until a few years ago, Oncidium was a vegetative diverse genus with more than 400 species, composed of plants with more or less similar flowers (predominantly yellow, with some brown spotting, quite often bearing complex elaiophores). Williams et al. (2001) have demonstrated that the genus Oncidium, as formely circumscribed, represents a polyphyletic assemblage of plants defined by its morphologically similar flowers which are attractive to similar pollinators (mostly oil-gathering bees of family Apidae). Instead, "Oncidium-like" flowers have arisen several times in subtribe Oncidiinae (Williams et al. 2001).

ACKNOWLEDGEMENTS. Both authors acknowledge their advisor, Maria do Carmo E. Amaral, from the Botany Department of Universidade Estadual de Campinas, Brazil. This contribution was made possible through grants conferred by FAPESP (Fundação ao Amparo à Pesquisa do Estado de São Paulo, processes 01/08958-1 and 02/021617) for both authors. 


\section{Literature Cited}

Chase, M.W. 1986. A reappraisal of the Oncidioid Orchids. Syst. Bot. 11 (3): 477-491.

Dressler, R.L. 1993. Phylogeny and classification of the orchid family. Dioscorides Press, Oregon.

Pabst, G. \& F. Dungs. 1977. Orchidaceae Brasilienses Vol. 2. Hildesheim, Brucke.

Singer, R.B. 2002. The pollination mechanism in Trigonidium obtusum Lindl. (Orchidaceae: Maxillariinae): sexual mimicry and trap-flowers. Ann. Bot. London 89 (2): 157-163.
Whitten, W.M., N.H. Williams \& M.W. Chase. 2000. Subtribal and generic relationship of Maxillarieae (Orchidaceae) with emphasis on Stanhopeinae: combined molecular evidence. Amer. J. Bot. 87 (12): 18421856.

Williams, N.H., M.W. Chase, T. Fulcher \& W.M. Whitten. 2001. Molecular Systematics of the Oncidiinae based on evidence from four DNA sequence regions: expanded circumscriptions of Cyrtochylum, Erycina, Otoglossum and Trichocentrum and a new genus (Orchidaceae). Lindleyana 16(3): 113-139.

Rodrigo Singer is a post-doctoral researcher at the Department of Botany of Universidade Estadual de Campinas (Unicamp), São Paulo, Brazil. Rodrigo has extensive field experience in Southeastern Brazil as well as with breeding systems and pollination biology studies of several Brazilian orchid groups. His current research activities involve phylogenetic, morphological, breeding systems and pollination biology studies of orchids from the subtribe Maxillariinae.

Samantha Koehler is a graduate student at the same institution. She recently completed a phylogenetic study of Bifrenaria. Her dissertation involves phylogeny, systematics and diversification of the Brazilian Maxillaria madida complex. 